\title{
LA PORTADA DE SAN MATEO Y LA LONJA DE LOS GANADEROS ZACATECANOS
}

\section{Por Federico Sescosse}

El Conde. Procedente de Andalucía, joven, sano y provisto de un temperamento poco común; lleno de ambiciones y dotado de grandes cualidades, llegó don Fernando de la Campa y Cos a tierras zacates. canas, tras de haber recorrido el peligroso camino "de la plata" que abriera un siglo antes Juan Núnez de Sallas ${ }^{1}$ y pacificara y trajinara con sus carretas un poco después, el siervo de Dios fray Sebastián de Aparicio.

Probó suerte, como todos, en el azaroso destino de la minería y las entrañas de nuestros cerros, generosamente, le dieron un caudal que habría de servir para iniciar el imperio territorial -agrícola y ganadero- más opulento del siglo xvirr.

Con mayor afición para asuntos de labranza y montería que para los obscuros quehaceres de la mina, don Fernando echó sobre una mula sus cuartos y ochavos y acompañándolos de los avíos más necesarios se fue a explorar "tierra adentro" hasta llegar a las tierras de la huicholería en donde fundó la hacienda de Ameca.

Trabajó con tesón y ahinco sobrehumanos y más adelante, entre asaltos de los indios, afrontados con más que menos fortuna y valor, se estableció en San Mateo de Valparaíso, en el sureste de Zacatecas, en donde casó y acrecentó su haber hasta que sus dominios comprendieron los poblados de Valparaíso, Lobatos, San Agustín del Vergel y las haciendas de Corrales, Ameca, Sauceda, Abrego, La Presa, El Centro, Trujillo, El Jaral, El Cubo, Gallinas, Cerro Prieto, La Encarnación, San Marcos, Agostadero, Pilotos, El Carro, Santa Elena, El Molino, la enorme y famosa de Juan Pérez, Santa Catarina, San Sebastián, Carboneras y La Tapona.

$\mathrm{Y}$ con todo este inmenso territorio bajo su égida y disfrutando de sus cuantiosísimas utilidades que, posteriormente habrian de utilizarse para construir el palacio de "La Condesa" en Zacatecas y los de Iturbide $y$ del Banco Nacional en la ciudad de México, don Fernando conservó sus hábitos de trabajo, su natural justiciero y caritativo y recibió de la corona el merecido título de Conde de San Mateo de

1 Eugenio del Hoyo, Cit. Informe de don Luis de Velasco a su sucesor. 
Valparaíso, como galardón por sus hazañas en las lides de la guerra de los chichimecas y sus triunfos en las empresas de la paz.

La portada. Gran señor como era, el Conde don Fernando erigió en San Mateo, centro de sus vastísimos dominios, un palacio digno de sus blasones y riquezas y cuyas enormes proporciones, su atalaya, sus largos claustros, sus grandes salas, sus inacabables caballerizas y establos, sus trojes y bodegas, su majestuosa escalera, tuvieron como adecuado proemio el frontispicio de piedra, compuesto por una sobria y esbelta arquería de dos plantas que, sobresaliendo del paño general de la fachada, servía de mirador al salón de recibir y regalaba con una hermosa vista sobre la extensión del valle flanqueado por el sur por las fragosidades de la sierra.

$Y$ para vestir y ornamentar el desnudo paramento que se alza hacia la izquierda en dirección a la capilla, digna también de su dueño, el conde mandó labrar con gran primor una amplia portada que sirviera de marco al vano por el cual habrian de entrar los grandes del reino a visitarlo y diera fe de su alcurnia y su grandeza.

Padrón seré. Sobre basas de dos toros bordeados de filetes al modo corintio, se levantan las jambas de fuerte molduración vertical, compuesta por un bocelón de garganta, casi exento, que corre formando un tablero con molduras secundarias en su interior y exterior, a la altura del dintel, para deslizarse horizontalmente y formar así una hache que enmarca el claroscuro de la puerta y se corona graciosamente con una clave ornamentada de follaje; como punto central de la atención, antes de continuarse hacia arriba para flanquear un distico, a manera de mote, que en un recuadro hundido, enlaza el tercio superior de las pilastras diciendo orgulloso: "Padrón" ${ }^{2}$ seré que viva eternizando las memorias del conde Don Fernando"; caso insólito en el panorama de nuestra arquitectura barroca civil, y más si se reflexiona en que es la misma arquitectura la que pregona la grandeza de su constructor.

Más arriba el fuerte entablamento, tan barroco como las jambas y el dintel, se adorna con un gracioso friso de retorcidas guirnaldas y se corona con la indispensable cornisa de alto vuelo y de múltiples ingletes con filos redondeados, para seguir en el segundo cuerpo con mayor riqueza y desenvoltura.

Vemos ahi dos guardias de bajorrelieve, con sus altas botas cazadoras, sus calzas ajustadas, su casaca adornada en el pecho con una inexplicable media luna y tocados con un birrete con pluma, a la manera de pajes de monteria, todo esto siguiendo la usanza de la época.

2 Padrón: con el significado antiguo de "testimonio". 
En medio el escudo del Conde, borrado a fuerza de cinceles y martillos por orden de don Guadalupe Victoria, dejó un espacio en blanco, sólo ocupado desde entonces, por el águila que el rey de armas puso a modo de cimera, para sostener con sus garras la corona condal y que, por suerte, se escapó a las feroces mordidas de la piqueta iconoclasta antiespañola.

El desconocido alarife puso un marco circundando el escudo (como si se tratara de una ventana), ornamentado fuertemente con plástica orla de imaginarias hiedras saliendo de sus tiestos, con jambas sobre plintos que encierran la fecha de construcción: 1738, separados por un alféizar con fleco o guardamalleta, también ornado de hojarasca y un cornisamento formado por un cimacio que se ondula en dos arcos invertidos con un tramo horizontal al centro.

Este marco riquísimo se remata con una graciosa cruz de cintas entrelazadas en petatillo, flanqueada por dos pequeños pináculos que también protegen una pequeña escultura de la Virgen Inmaculada puesta sobre el saliente del cornisamento y que, en si, es una obra de arte popular interesante por la agudeza de los picos de las bocamangas, el zigzagueante plegamiento de la túnica y de la cabellera y la espiral en que se envuelve el manto y que sólo se puede admirar si se ve desde abajo.

Adviértese que esta escultura no fue pensada por el alarife para formar parte orgánica de la portada pues el lugar en que se encuentra no es adecuado y creemos que sólo la devoción del Conde o de sus sucesores fue lo que hizo que fuera puesta en el sitio en que se encuentra.

Hay en todo este trabajo de principios del siglo xvir una riqueza de molduración y de ornato que presagia los desbordamientos decorativos que habrian de venir, pero al mismo tiempo se observa una cierta mesura y sobriedad de ejecución que coinciden con algunos ejemplos del siglo anterior.

Las claves, el friso y el marco del escudo corresponden a no dudar a la modalidad del barroco que clasifica acertadamente el investigador Manuel González Galván ${ }^{3}$ como "barroco helicoidal o salomónico", pero a las pilastras que hacen de jambas no podemos fácilmente ponerles su marbete, pues la profundidad, vigor y exaltación del claroscuro, lo acusado del cuello del bocel y en general el partido que tomó el artífice, nos impulsan más bien a asociarla con un tipo de barroco

3 "Modalidades del Barroco Mexicano", en Anales del Instituto de Investigaciones Estéticas, vol. vin, núm. 30. México, 1961. 
purista, ${ }^{4}$ como el de la Compañía de Zacatecas, en donde este tratamiento de la cara de las pilastras reaparece en las portadas de la antesacristía, construida entre los años de 1746 y 1749 .

La destrucción. Desafortunadamente, la suerte que este palacio ha corrido en estos últimos años no puede ser más dolorosa e irremediable; tras de haberse incendiado una parte, quedó abandonado y las vigas de los techos, las puertas y ventanas pasaron poco a poco a mar nos de gentes sin escrúpulos que las utilizaron en otras construcciones o las vendieron para su provecho, dejando sólo ruinas desoladas entre las cuales es peligroso caminar por el inminente riesgo de derrumbes.

Sólo la fachada insigne permanecia casi incólume pero difícilmente accesible y sometida al continuo peligro de sufrir mutilaciones o alteraciones.

El traslado a Zacatecas. Tomando en consideración lo anterior y sopesando las grandes dificultades para darla a conocer, en vista de los problemas que presenta el poder llegar a San Mateo, juntamente con la práctica imposibilidad de restaurar el palacio de los condes, para hacerlo atractivo a los improbables visitantes, el que esto escribe decidió, a principios del año pasado, hacer algunas gestiones tendientes a conseguir el traslado de la fachada a algún lugar adecuado, en donde pudiera salvaguardarse y ser admirada por propios y extraños.

En el mes de mayo, la Unión Ganadera Regional decidió construir en la ciudad de Zacatecas un edificio de grandes proporciones que habría de servir de lonja a sus socios y tendría un anexo para albergar la exposición que celebra anualmente. En él se pensó que podría colocarse la portada, para salvaguardarla y para aumentar el acervo artístico de Zacatecas.

Como se encontraba mutilada, sin el escudo original, se pensó también en la conveniencia de rehacerlo aún a costa de introducir un elemento de reciente factura en el antiguo conjunto, pues ocurria que el cuadro vacío coronado inexplicablemente por un águila, producía en el espectador una viva reacción de extrañeza y disgusto.

El paño de fachada en que se colocó la obra antigua se acompañó por el lado norte con una loggia copiada de la existente en San Mar teo y en la entrada a la exposición se realizó una simplificada réplica de la portada para lograr unidad y armonía. 
DOI: http://dx.doi.org/10.22201/iie.18703062e.1965.34.807

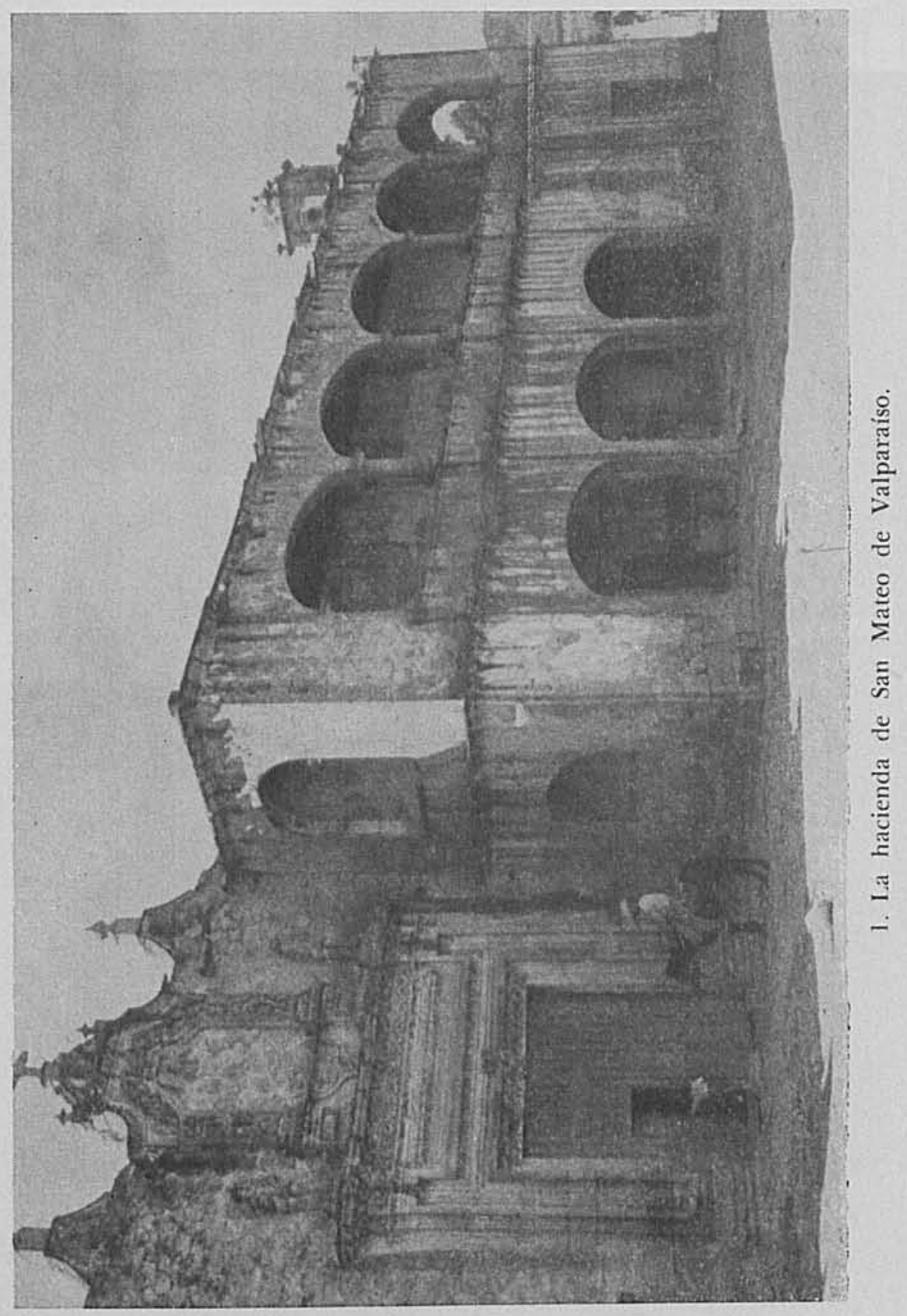


DOI: http://dx.doi.org/10.22201/iie.18703062e.1965.34.807

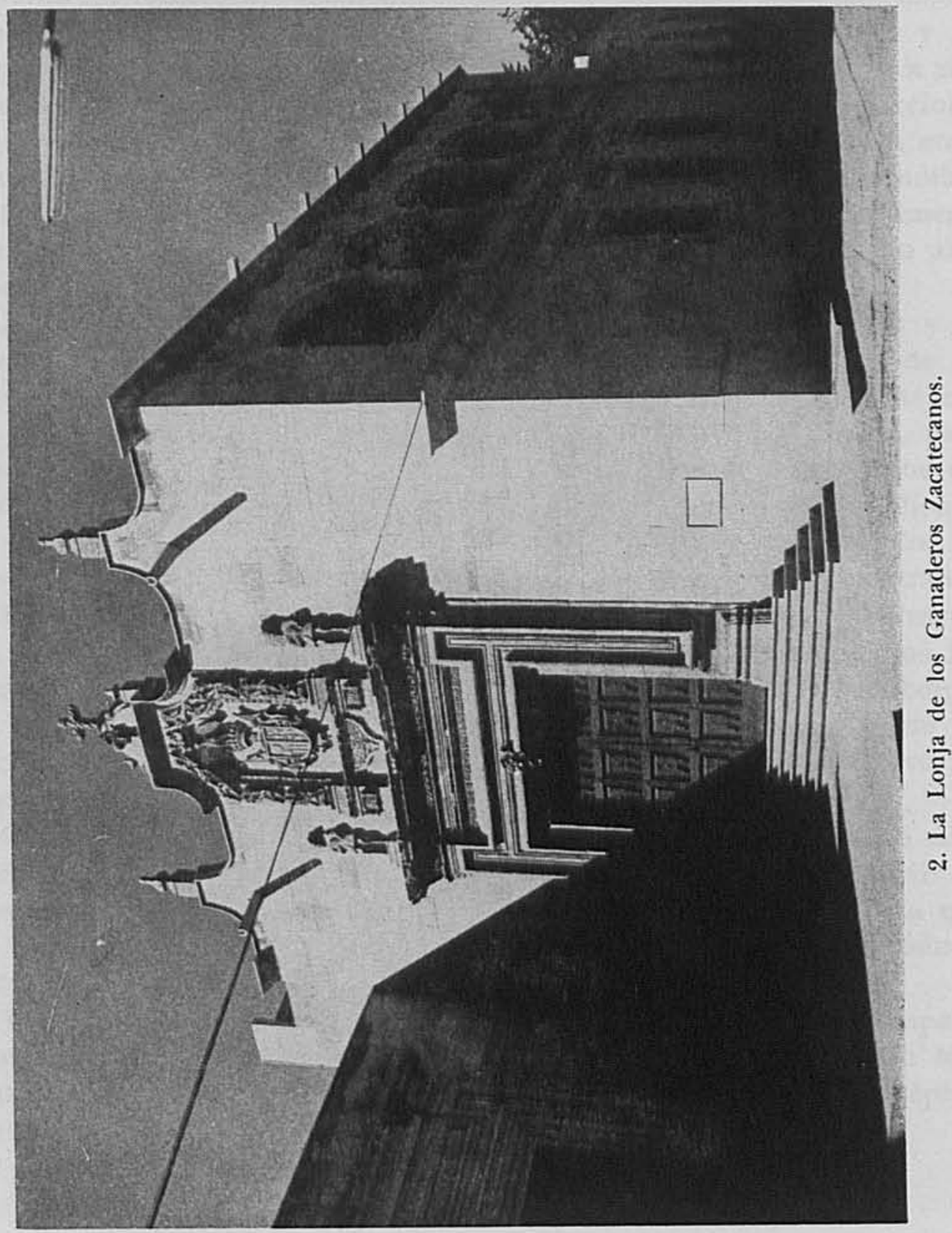




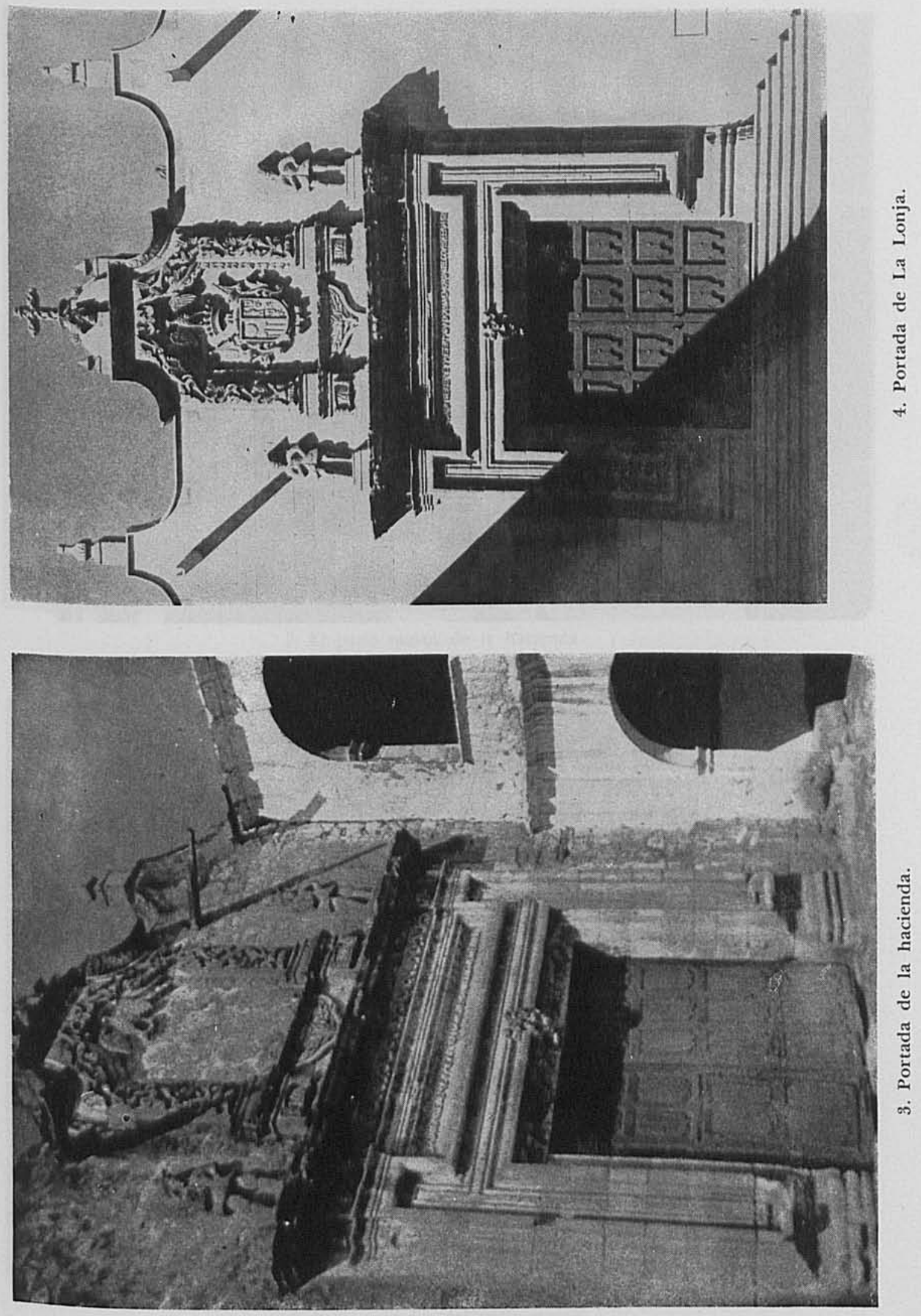


DOI: http://dx.doi.org/10.22201/iie.18703062e.1965.34.807
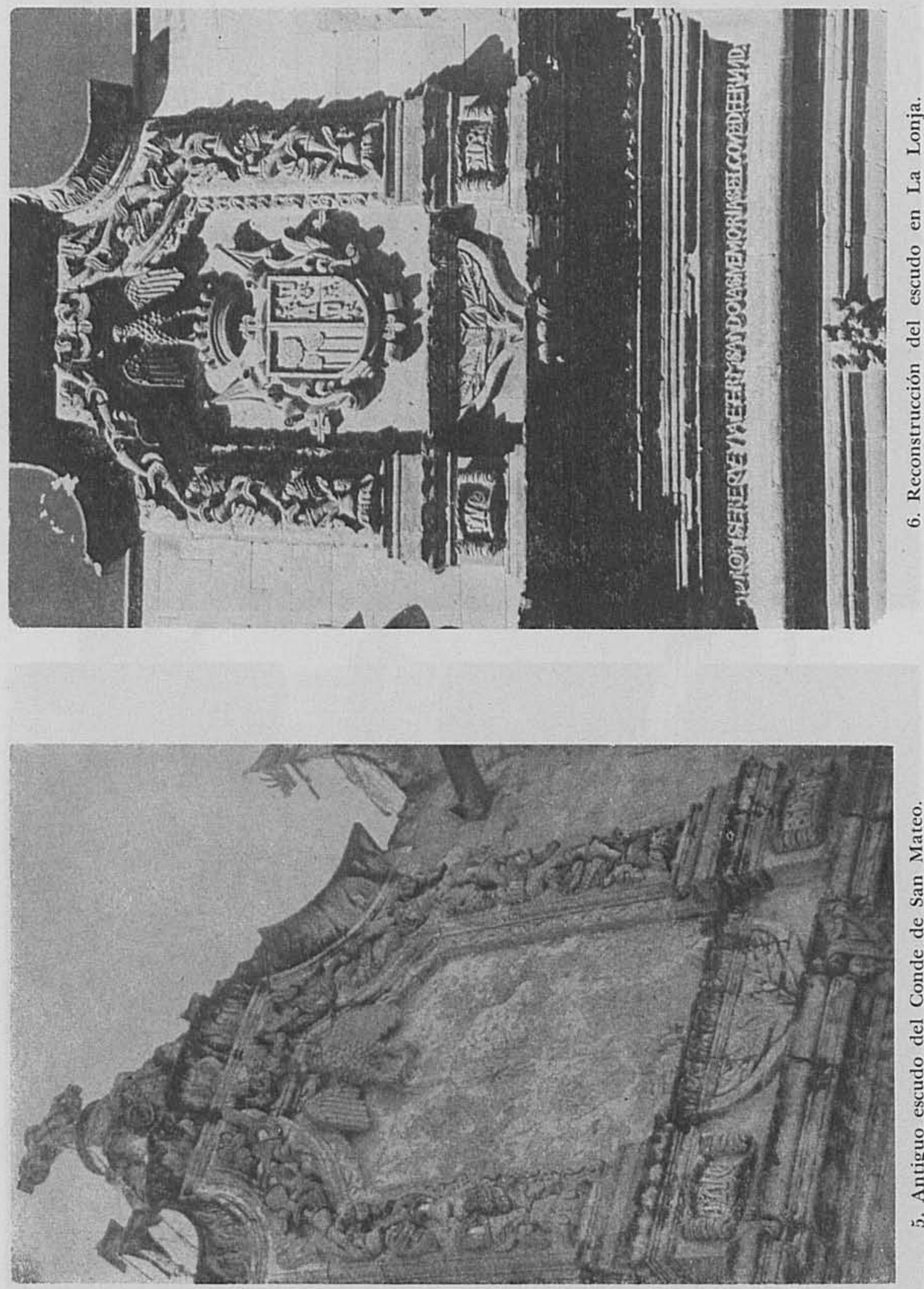

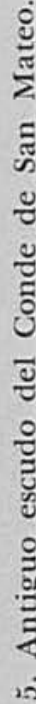




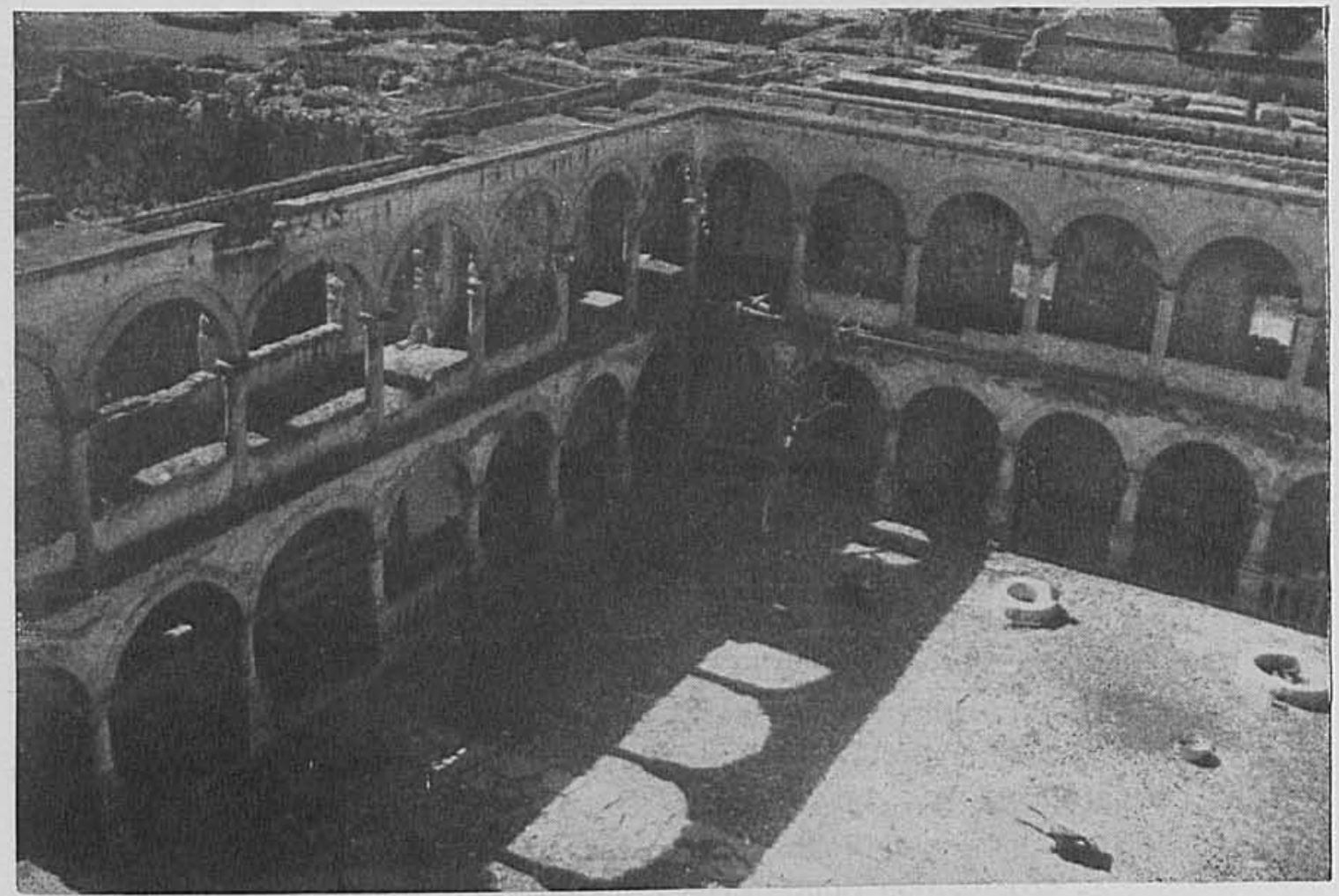

7. El patio mayor de la hacienda.

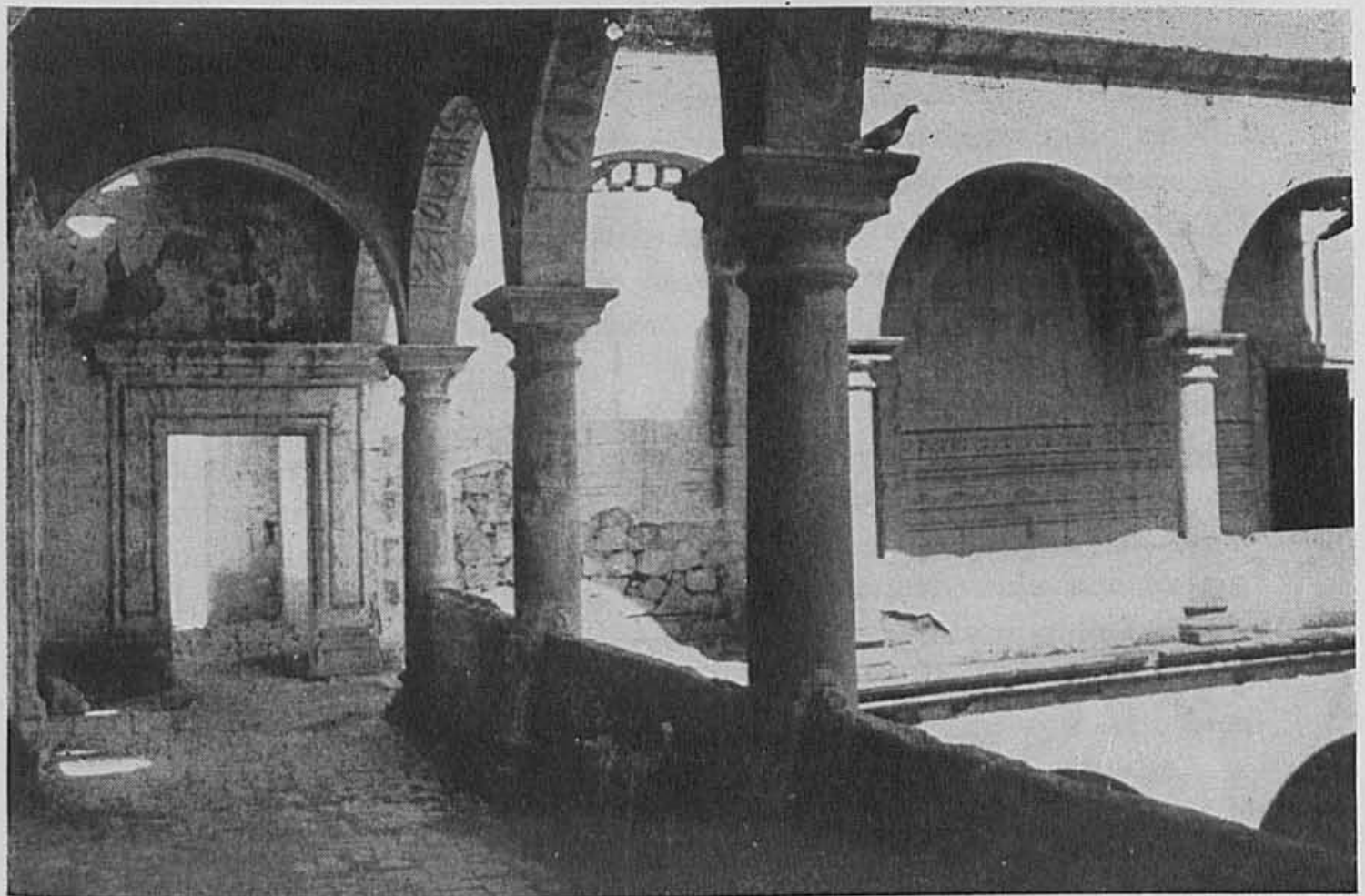

